\title{
O SENTIDO ONTOLÓGICO DA ALTERIDADE SEGUNDO MERLEAU-PONTY
}

\author{
THE ONTOLOGICAL SENSE OF THE ALTERITY ACCORDING TO MERLEAU-PONTY
}

Renato dos Santos*

\section{RESUMO}

O presente artigo analisa a noção de alteridade nos últimos textos de Merleau-Ponty. Mostra, ainda, como o filósofo supera o problema do espírito, que sempre impediu a relação intersubjetiva, por meio da reabilitação ontológica da noção de estrutura, pensada como carne (La chair). A relação com o outro não recai mais na consciência da subjetividade, visto que ambos estão presos num mesmo tecido gestáltico, como quiasmas, de tal modo que toda realidade sensível é feita desse mesmo estofo primordial. A diferenciação, portanto, ocorre no próprio mundo enquanto figura sobre fundo.

PALAVRAS-CHAVES: Quiasma. Gestalt. Alteridade. Merleau-Ponty.

\section{ABSTRACT}

This article analyzes the notion of otherness in the last Merleau-Ponty texts. It also shows how the philosopher overcomes the problem of the spirit, which always prevented the intersubjective relationship, through the ontological rehabilitation of the notion of structure, thought as meat (La chair). The relation with the other no longer rests on the consciousness of subjectivity, since both are trapped in the same gestalt tissue, as chiasmas, in such a way that every sensible reality is made of the same primordial upholstery. Differentiation therefore occurs in the world itself as a figure on the background.

KEY-WORDS: Chiasm. Gestalt. Alterity. Merleau-Ponty.

\section{INTRODUÇÃO}

\begin{abstract}
Eu é um outro. Azar da madeira que se descobre violino, e danem-se os inconscientes que discutem sobre o que ignoram completamente!

[...] Pois Eu é um outro. Se o cobre desperta clarim, não é por sua culpa. Isso me é evidente: assisto à eclosão de meu pensamento; contemplo-o; escuto-o; faço um movimento com o arco; a sinfonia faz seu movimento no abismo, ou de um salto surge na cena. (RIMBAUD, 1871/2006).
\end{abstract}

Antes de adentrarmos propriamente na discussão da problemática que norteia nossa investigação, qual seja, a relação entre o eu e o outro, propomos começar retornando no início da obra $O$ visível e o invisível (MERLEAU-PONTY, 2014), a fim de trazermos, à baila, a

\footnotetext{
* Doutorando em Filosofia pela Pontifícia Universidade Católica do Paraná (PUCPR), Brasil, e pela Universidade de Coimbra (UC), Portugal. Lattes: http://lattes.cnpq.br/7526944411424050. E-mail: renatodossantos1@hotmail.com.
} 
noção de fé perceptiva, a qual será preponderante para compreendermos como a relação com outrem se encontra, primeiramente, ancorada numa dimensão, como veremos, de sentimento selvagem.

É verdade que Merleau-Ponty já afirmara algo semelhante em 1945, mais exatamente através da noção de consciência pré-reflexiva e a vida perceptiva no geral. Porém, tratava-se aí, conforme comenta Ferraz, mais de explicitar o sentido da percepção, precisamente no momento de mostrar como "a atividade perceptiva adere ao mundo mesmo sem dispor de dados absolutamente certos e mesmo sem realizar verificações teóricas que atestem a certeza de suas visadas" (FERRAZ, 2009, p. 213, grifo do autor).

Na nota de trabalho, datada de fevereiro de 1960, Merleau-Ponty explicita o itinerário de seu projeto ontológico. Segundo o filósofo, o ponto de partida ${ }^{1}$ de sua ontologia está "onde Sartre tem seu ponto de chegada, no Ser retomado pelo para $\mathrm{Si}$ - Este é seu ponto de chegada porque ele parte do ser e da negatividade e constrói sua união" (MERLEAU-PONTY, 2014, p. 216, grifo do autor). Ademais, para a ontologia sartriana, que é "uma ontologia do interno, não há que construir a transcendência, ela existe de início, como Ser forrado de nada" (MERLEAU-PONTY, 2014, p. 216, grifo do autor).

Não se trata mais de pensar o Ser enquanto duplicado de Nada, ou seja, como "mistura" entre um e outro, como fez Sartre. Para Merleau-Ponty, desta vez, o negativo não quer dizer absolutamente nada, "e o positivo também não (são sinônimos), e isso não por apelo a uma vaga 'mistura' do ser e do nada" (MERLEAU-PONTY, 2014, p. 216). Outrossim, na ontologia merleau-pontyana não há mais a concepção de oposição entre o Ser e o Nada, não há contradição entre um e outro. Contudo, se o Nada não é mais contraditório do Ser, o que será ele então?

\section{A ONTOLOGIA DA CARNE}

Na nota de maio de 1960, Merleau-Ponty (2014, p. 232) assevera: "o sensível, o invisível deve ser para mim a ocasião de dizer o que é o nada - o nada não é nada mais (nem nada menos) que o invisível”. A relação entre o ser e o nada é, por sua vez, conforme esclarece Moutinho, a relação entre visível e invisível. Porém, com a grande diferença de que

\footnotetext{
${ }^{1}$ Em outra passagem Merleau-Ponty (2014, p. 9, grifos do autor) acrescenta: "Nosso ponto de partida não será: o ser é e o nada não é - nem mesmo: só há o ser - fórmula de um pensamento totalizante, de um pensamento de sobrevoo - mas há o ser, há o mundo, há alguma coisa, no sentido forte em que o grego fala elemento, há coesão, há sentido".
} 
o visível não é presença objetiva, "um positivo objetivo, e o invisível uma negação dele, como em Sartre” (MOUTINHO, 2004, p. 16). Para Merleau-Ponty, o invisível não é contraditório do visível. Ao contrário: "o visível possui, ele próprio, uma membrura de invisível, e o invisível é a contrapartida secreta do visível, não aparece senão nele" (MERLEAU-PONTY, 2014, p. 200).

É importante notarmos que Merleau-Ponty fala de uma membrura, que é responsável por possibilitar a indissociabilidade entre o visível e o invisível. Quer dizer, a membrura não faz a união de dois polos objetivos separados, mas ela própria é a condição de possibilidade para que eles existam, que o visível faça projetar o invisível. É, pois, nessa direção que a ontologia de Merleau-Ponty se encaminha, qual seja, de pensar os polos não mais em termos de contradição, como excludentes um ao outro, mas através da cumplicidade ontológica que os entrelaça por meio de uma estrutura.

A seguir, mostraremos como Merleau-Ponty elabora sua ontologia da carne através da noção renovada de gestalt. Trata-se de um uso peculiar da noção de estrutura feito pelo filósofo que salvaria definitivamente a filosofia do subjetivismo e do objetivismo. A respeito disso, numa de suas notas de trabalho, o próprio Merleau-Ponty (2014, p. 183, grifos do autor) afirma: "a saber, de uma presença a Si que é uma ausência de si, contato com Sigo pela distância em relação a Si - Figura sobre fundo, 'Etwas' o mais simples - a Gestalt tem a chave do problema do espírito".

Desse modo, o uso da noção de estrutura não estaria somente designando a dimensão epistemológica da percepção - conforme realizado na obra de 1945 -, mas, precisamente, em servir como “princípio explicativo e como a condição do 'ser no mundo', pois não apenas percebo uma figura sobre um fundo, mas me encontro no mundo como uma figura sobre um fundo" (FALABRETTI, 2013, p. 321).

De acordo com Falabretti, a primeira manifestação da gestalt que encontramos está na dimensão da passividade, enquanto experiência primordial na qual as coisas e os outros se fazem presentes em nós: "trata-se de uma condição primordial esquecida, na medida em que passamos da ordem do sentir para o pensar e reconhecemos o cogito e as coisas como centros antinômicos destinados a realizar funções distintas" (FALABRETTI, 2013, p. 322). A passividade é o momento originário no qual não há sobreposição entre uma dimensão passiva e outra ativa. Para Merleau-Ponty, trata-se de conceber as noções "solidárias de ativo e passivo, de tal maneira que não nos coloquem mais diante da antinomia de uma filosofia que 
explica o ser e a verdade, mas que não explica o mundo, e de uma filosofia que explica o mundo, mas desenraiza do ser e da verdade” (MERLEAU-PONTY, 2014, p. 51).

O exame da passividade nos permite compreender como a verdade não é despontada de um cogito constituinte ou do mundo das relações objetivas. Ela, na verdade, antes se origina da relação estrutural do Ser e do mundo primordial, fundada por uma circularidade que, primeiro, é "sustentada pelo Ser, e o Ser pela verdade como uma figura, podemos dizer, amparada pelo fundo" (FALABRETTI, 2013, p. 323). A passividade, dessa maneira, nos revela que o mundo e o Ser não são constituídos de um polo, ou substância da ordem do Emsi ou do Para-si, mas estruturados, essencialmente, por uma dimensão gestáltica. Conforme esclarece Merleau-Ponty, em uma nota de rodapé, ao analisar a ontologia negativista sartriana:

\footnotetext{
O 'núcleo de ser' duro de que Sartre fala. Não há núcleo com, em torno do [não?] que seria eu (negações, brilho na superfície do ser). O ser é transcendente, quer dizer justamente: é aparências cristalizando-se, é pleno e VAZIO, é GESTALT com horizonte, é duplicidade dos planos, ele é, ele mesmo, VERBORGENHEIT - é ele quem se percebe, como é ele quem em mim fala. (MERLEAU-PONTY, 2014, p. 80, grifos do autor).
}

O que podemos extrair dessa nota é, justamente, como o projeto ontológico de Merleau-Ponty difere radicalmente dos modelos da metafísica forjados pela tradição filosófica e, finalmente, por Sartre. O Ser não é mais definido como entidade unívoca, no sentido de ser certa substância definida por uma identidade. O Ser, a partir desse momento, é gestalt, ou seja, "é um princípio de distribuição, o pivô de um sistema de equivalências, é o Etwas de que os fenômenos parcelares serão a manifestação" (MERLEAU-PONTY, 2014, p. 193, grifos do autor).

No entanto, como já havíamos comentado anteriormente, não se trata de uma noção de estrutura entendida como um mecanismo epistemológico, tampouco, conforme a Gestalttheorie concebeu, como realidade objetiva. A noção de estrutura - gestalt -, aqui, deve ser compreendida como o próprio tecido que constitui o mundo, a realidade sensível. Nessa perspectiva, conforme esclarece Mario Teodoro Ramírez, na obra La filosofia del quiasmo, "pensar rigorosamente a estrutura quer dizer pensá-la como carne, isto é, como originária confusão do sensível e do inteligível, da matéria e do espírito, da objetividade e da subjetividade" (RAMÍREZ, 2013, p. 118). 
Para tanto, cabe esclarecer, antes de qualquer coisa, o que exatamente Merleau-Ponty entende pela noção de carne. O que é, finalmente, esse conceito que "não há nome na filosofia tradicional para designá-lo?” (MERLEAU-PONTY, 2014, p. 135) Segundo o filósofo:

\footnotetext{
A carne não é matéria, não é espírito, não é substância. Seria preciso, para designála, o velho termo 'elemento', no sentido em que era empregado para falar-se da água, do ar, da terra e do fogo, isto é, no sentido de uma coisa geral, meio caminho entre o indivíduo espaço-temporal e a ideia, espécie de princípio encarnado que importa um estilo de ser em todos os lugares onde se encontra uma parcela sua. Nesse sentido, a carne é um 'elemento' do Ser. (MERLEAU-PONTY, 2014, p. 136, grifos do autor).
}

A carne, desse modo, é uma espécie de princípio que constitui as coisas e o mundo. Ela está em tudo, mas não se reduz a um determinado ente em particular. Para Merleau-Ponty (2014, p. 143), é preciso compreender a carne "não a partir das substâncias, corpo e espírito, pois seria então a união dos contraditórios, mas dizíamos, como elemento, emblema concreto de uma maneira de ser geral". Assim, a carne se configura como nervura do Ser, um estofo de sustentação da condição de possibilidade das coisas, ou como falamos anteriormente, é gestalt, porquanto "permite a abertura para que o corpo e as coisas sejam visíveis na mesma medida em que são tangíveis e videntes” (FALABRETTI, 2013, p. 336).

É no capítulo "O entrelaçamento - o quiasma”, da obra $O$ visível e o invisível, que podemos verificar, de modo mais detalhado, o papel que a noção de carne cumpre no projeto ontológico de Merleau-Ponty. Tomando como ponto de partida a reversibilidade entre senciente-sensível, o filósofo radicaliza a experiência de nosso contato com o mundo revelado pela fé perceptiva. Na experiência da visão, por exemplo, é preciso superar a ideia de que aquele que vê é dotado de uma natureza divergente daquilo que é visto, ou seja, do visível, o que implicaria que o vidente se tornasse um "estranho ao mundo que olha" (MERLEAU-PONTY, 2014, p. 131).

Ademais, a experiência do "ver" não é uma ação deflagrada pelo cogito, visto que o próprio olhar está enredado pela carne do visível. Não há, aqui, um vidente vazio que se abriria, em seguida, para as coisas visíveis, "mas sim algo de que não poderíamos aproximarnos mais a não ser apalpando-o com o olhar [...], porquanto o próprio olhar as envolve e as veste com sua carne” (MERLEAU-PONTY, 2014, p. 128). Nesse sentido, a visão possui essa enigmática característica de envolver as coisas mas, ao mesmo tempo, é também envolvida 
por elas. As coisas não se encontram de maneira inerte diante de mim, o visível não é estático, entidade pura, mas me envolve e me toca.

$\mathrm{Na}$ visão das cores, exemplifica Merleau-Ponty - e aqui, em específico, o vermelho é preciso compreender que ele não é um "quale, uma película de ser sem espessura, mensagem ao mesmo tempo indecifrável e evidente, [...] em suma, que nada há a dizer" (MERLEAU-PONTY, 2014, p. 129, grifo do autor). O vermelho, ao contrário, antes "emerge de uma vermelhidão menos precisa e menos geral onde meu olhar estava preso e mergulhava antes de fixá-lo" (MERLEAU-PONTY, 2014, p. 129, grifo do autor).

O que constitui a cor não é um aglomerado de átomos que, juntos, formariam o vermelho. A cor, diz Merleau-Ponty, se dá por ligação entre o vermelho da camisa, da bandeira, de uma pintura etc., constituindo, assim, "uma espécie de nó na trama do simultâneo e do sucessivo. É uma concreção da visibilidade, não um átomo” (MERLEAU-PONTY, 2014, p. 129). Em outros termos, trata-se de uma carne de vermelhidão que contém todas as variantes da cor vermelha, ou, se quiser, uma Gestalt.

Em $O$ olho e o espírito, última obra publicada em vida por Merleau-Ponty, a visão também é pensada a partir dessa radical imbricação com a carne do mundo: "o mundo visível e de meus projetos motores são partes totais do mesmo ser" (MERLEAU-PONTY, 2013, p. $19)^{2}$. Sendo a visão entrelaçada com aquilo que se vê, ela passa a ser sinestésica, na medida em que ela articula todos os sentidos no momento em que entra em contato com as coisas.

É o que Merleau-Ponty constata, por exemplo, nas pinturas de Cézanne, as quais proporcionam com o que a natureza, as frutas pintadas se mostrem para o olho como "vivas" e, muitas vezes, com a impressão de serem até "comestíveis", no caso das frutas, pois a visão, aqui, é entendida como aquilo que nos faz "entrar" na coisa vista, em sua carne, por meio da carne do vidente: "nós vemos a profundidade, o aveludado, a maciez, a dureza dos objetos Cézanne dizia mesmo: seu cheiro" (MERLEAU-PONTY, 2013, p. 134, grifo do autor). Ver efetivamente um quadro que possibilite a abertura para a experiência da sinestesia implica percorrer pela sua composição harmoniosa das cores, dos objetos contidos em sua profundidade, de maneira que seus signos nos conduzam para "junto deles", ou seja, nos solicitem para junto de sua carne.

\footnotetext{
${ }^{2}$ Para Merleau-Ponty, o pintor é o que mais tem por claro tal premissa, justamente por sempre se "utilizar" de seu corpo para realizar a pintura, ou seja, "é oferecendo seu corpo ao mundo que o pintor transforma o mundo em pintura” (MERLEAU-PONTY, 2013, p. 19).
} 
Segundo Merleau-Ponty (2013, p. 52), “é preciso tomar ao pé da letra o que nos ensina a visão: que por ela tocamos o sol, as estrelas, estamos ao mesmo tempo em toda parte, tão perto dos lugares distantes quanto das coisas próximas". Ou ainda, conforme enfatiza Merleau-Ponty (2014, p. 130): “o olhar, dizíamos, envolve, apalpa, esposa as coisas visíveis. Como se estivesse com elas numa relação de harmonia preestabelecida, como se as soubesse antes de sabê-las, move-se à sua maneira, em seu estilo sincopado e imperioso". Desse modo, o mundo, as coisas visíveis, não se encontram diante de mim, não estão como objeto frente a um sujeito. Estou, antes de tudo, envolvido com elas - enquanto quiasma -, preso em seu tecido, do qual também sou constituído corporalmente ${ }^{3}$.

Considerando que o vidente efetiva sua visão a partir da abertura do visível que se almeja, ou seja, que "quem vê não pode possuir o visível a não ser que seja por ele possuído" (MERLEAU-PONTY, 2014, p. 131), é preciso admitir que o vidente se torna visível, e por imbricação ${ }^{4}$, quem vê se torna, igualmente, visto. Todavia, isso somente é possível pelo fato de que o vidente possui um corpo que é feito da mesma carne do visível. Quer dizer, o corpo é o que torna possível a junção direta entre nós e as coisas pela sua "ontogênese, soldando um a outro os dois esboços de que é feito, seus lábios: a massa sensível que ele é e a massa de onde nasce por segregação, e à qual, como vidente, permanece aberto" (MERLEAU-PONTY, 2014, p. 132).

Assim, como podemos notar, "o corpo interposto não é propriamente coisa, matéria intersticial, tecido conjuntivo, mas sensível para si” (MERLEAU-PONTY, 2014, p. 132). Isso impede, por exemplo, de afirmar que a cor é vista, ou que a superfície é apalpada pelo corpo. Tais afirmações encontrariam sua verdade se o corpo não fosse feito da mesma carne do mundo, e não estivesse encarnado junto às coisas. De sorte que, sendo o corpo um sensível exemplar, ele é "o único meio que possuo para chegar ao âmago das coisas, fazendo-me mundo e fazendo-as carne" (MERLEAU-PONTY, 2014, p. 132).

Desse modo, o corpo é o que possibilita aquele que o habita e "o sente de sentir tudo o que de fora se assemelha" (MERLEAU-PONTY, 2014, p. 132). Estando o corpo emaranhado

\footnotetext{
${ }^{3}$ Cabe frisar, segundo Falabretti (2013, p. 329, grifo do autor), que "não dominamos o visível e não somos dominados por ele. No enigma da visão, envolvemos, mas não encobrimos o visível, interrogamos e somos interrogados, mas não instituímos o visível como, de certo modo, uma figura, ambiguamente, não suprime o seu fundo quando depende dele e é por ele sustentada. Assim, as coisas não existem como entes puros, elas coexistem e se comunicam como sencientes-sentidas, como parte de uma mesma gestalt".

4 “Essa extraordinária imbricação, sobre a qual não se pensa suficiente, proíbe conceber a visão como uma operação de pensamento que ergueria diante do espírito um quadro ou uma representação do mundo, um mundo da imanência e da idealidade. Imerso no visível por seu corpo, ele próprio visível, o vidente não se apropria do que vê; apenas se aproxima dele pelo olhar, se abre ao mundo.” (MERLEAU-PONTY, 2013, p. 19).
} 
no tecido das coisas, elas próprias o atraem integralmente, incorporando-o, e pelo mesmo movimento se comunica com "as coisas sobre as quais se fecha, essa identidade sem superposição, essa diferença sem contradição, essa distância do interior e do exterior, que constituem seu segredo natal” (MERLEAU-PONTY, 2014, p. 132) ${ }^{5}$.

Assim como na experiência da visão aquele que vê também é visto, no exemplo tátil da mão que toca a outra a consequência da reversibilidade é a mesma. Não há, aqui, dicotomia que faça com que uma das minhas mãos seja objeto para a outra, a qual ocuparia a posição de sujeito. Ambas as mãos são, ao mesmo tempo, tocante-tocada.

Há um círculo do palpado e do palpante, o palpado apreende o palpante; há um círculo do visível e do vidente, o vidente não existe sem existência visível; há até mesmo inscrição do palpante no visível, do vidente no tangível e reciprocamente; há, enfim, propagação dessas trocas para todos os corpos do mesmo tipo e do mesmo estilo que vejo e toco - e isso pela fundamental fissão ou segregação do senciente e do sensível, que, lateralmente, faz os órgãos de meu corpo entrarem em comunicação, fundando a transitividade de um corpo a outro. (MERLEAU-PONTY, 2014, p. 139).

Tanto na experiência da visão quanto do tato, a estrutura relacional que as assegura é a mesma: o tocante é tocado e o vidente é visível. Como diz Merleau-Ponty (2014, p. 130), esse cruzamento, ou entrelaçamento, são entradas do mesmo mundo: "os dois sistemas se aplicam um sobre o outro como as duas metades de uma laranja”. Ou, se preferir, uma figura sobre um fundo, amparadas no mesmo Ser.

Como comentamos anteriormente, o corpo próprio $^{6}$ é de tal modo que permite ser, concomitantemente, vidente e visível. Dirigindo-se ao mundo, ele é invadido pelas coisas, é tocado por aquilo que toca. É coerente observarmos a belíssima passagem na obra $O$ olho e $o$ espírito, na qual Merleau-Ponty retoma uma citação de André Marchand. Diz ele: "Numa floresta, várias vezes senti que não era eu que olhava a floresta. Certos dias, senti que eram as árvores que me olhavam, que me falavam.” (MERLEAU-PONTY, 2013, p. 26). Nessa radical encarnação do corpo com as coisas, com a carne do mundo, do vidente com o visível, "não se sabe mais quem vê e quem é visto" (MERLEAU-PONTY, 2013, p. 26).

\footnotetext{
${ }^{5}$ Numa nota de rodapé, Merleau-Ponty $(2014$, p. 132) acrescenta: "pode-se dizer que percebemos as próprias coisas, que somos o mundo que se pensa - ou que o mundo está no âmago de nossa carne. Em todo o caso, reconhece-se uma relação corpo-mundo, há ramificação de meu corpo e ramificação do mundo e correspondência do seu dentro e do seu fora, do meu dentro e do seu fora".

6 "Um corpo humano está aí quando, entre vidente e visível, entre tocante e tocado, entre um olho e outro, entre a mão e a mão se produz uma espécie de recruzamento, quando se acende a faísca do senciente-sensível, quando se inflama o que não cessará de queimar, até que um acidente do corpo desfaça o que nenhum acidente teria bastado para fazer." (MERLEAU-PONTY, 2013, p. 21).
} 
Aquilo que falamos da passividade é retomado, aqui, por Merleau-Ponty. Trata-se da condição estrutural pela qual existimos enquanto sujeitos corpóreos com as coisas do mundo ou, ainda mais radicalmente, com tudo aquilo que pertence a essa imensa carne, da qual também fazemos parte. A respeito disso, arremata Merleau-Ponty:

\footnotetext{
Visível e imóvel, meu corpo conta-se entre as coisas, é uma delas, está preso no tecido do mundo, e sua coesão é a de uma coisa. Mas, dado que vê e se move, ele mantém as coisas em círculo a seu redor, elas são um anexo ou um prolongamento dele mesmo, estão incrustadas em sua carne, fazem parte de sua definição plena, e o mundo é feito do estofo mesmo do corpo. (MERLEAU-PONTY, 2013, p. 20).
}

Sendo assim, não há possibilidade, seguramente, de se pensar uma subjetividade, ou essência, fora do mundo, encarnada com as coisas, numa relação quiasmática. Encontramosnos presos na estrutura carnal do mundo, como figura-fundo: "não há outro sentido além do carnal, figura e fundo - Sentido $=$ seu deslocamento, sua gravitação (aquilo que eu chamava ‘escapamento' na Fenomenologia da Percepção)” (MERLEAU-PONTY, 2014, p. 238, grifos do autor). Afirmar que estamos encarnados com as coisas significa dizer que a carne "é pacto de nosso corpo com o mundo e pacto entre as coisas, entre as palavras e as ideias [...]. O quiasma, trabalhando a Carne por dentro, enlaça, cruza, segrega e agrega, reflexiona sem coincidir. Diferenciação" (CHAUI, 2002, p.111-112, grifos da autora).

No entanto, essa diferenciação somente é possível pelo fato de que, na ontologia merleau-pontyana, não temos mais um Ser perspectivista, tal como encontramos nas ontologias que se fundamentam a partir da noção do espaço euclidiano. Esta tem, por definição, "o modelo do ser perspectivo, é um espaço sem transcendência, positivo, rede de retas, paralelas entre si ou perpendiculares" (MERLEAU-PONTY, 2014, p. 196). O espaço topológico, ao contrário, permite estabelecer relações de vizinhanças e envolvimento entre as partes opostas, de modo que "funda o princípio selvagem do Logos - É este ser selvagem ou bruto que intervém em todos os níveis para ultrapassar os problemas da ontologia clássica" (MERLEAU-PONTY, 2014, p. 197, grifo do autor).

A verticalidade, enquanto Ser bruto, oblíquo, é justamente o que possibilita a relação quiasmática entre as coisas sem, com isso, suprimir um lado ou outro. É a profundidade que permite pensarmos em uma ontologia do Ser de indivisão e de diferenciação sem cair na dialética, na medida em que quantidade, qualidade, percepção e ideia "não são contrários, nem opostos, nem momentos de passagem negadora, mas 'núcleos de sentido', 'outras 
dimensões' que se interpenetram, passando cada qual pelos poros das outras" (CHAUI, 2002, p. 115).

Sob esse prisma, o mundo vertical é a abertura para o entrelaçamento carnal entre as coisas, o mundo e outrem. Numa nota datada de novembro de 1959, Merleau-Ponty enfatiza a profundidade - ou verticalidade - como a condição da carnalidade. É ela, diz o filósofo, "quem faz com que as coisas tenham uma carne: isto é, que oponham obstáculos à minha inspeção, uma resistência que é precisamente a sua realidade, sua 'abertura', o seu totum simul” (MERLEAU-PONTY, 2014, p. 203, grifos do autor).

Até aqui, procuramos apresentar a arquitetura da ontologia merleau-pontyana. Mostramos como, através da ressignificação da noção de gestalt, o filósofo encontrou a alternativa para a superação do problema do espírito, na medida em que colocou a subjetividade, o cogito, no seu devido lugar, qual seja, entrelaçado com as coisas, com o mundo e, como veremos, com outrem. Formando, assim, uma carne, a qual se configura como "coesão sem princípio", no sentido de não ter uma essência pré-determinada, como encontramos, por exemplo, nas metafísicas tradicionais. Ora, mas essa empreitada se efetiva em virtude de que o Ser bruto é vertical, Ser de profundidade, impedindo com que caiamos nas velhas amarras das ontologias clássicas que pensam a presença como identidade e coincidência, ou a dialética da tese-antítese-síntese.

Na seção seguinte, passaremos a discutir, finalmente, como é possível pensar a relação entre o eu e o outro nessa dimensão ontológica. Como a gestalt, enquanto carnalidade, poderia dissolver definitivamente o problema da relação com outrem? Ou ainda: estando a subjetividade presa no tecido do mundo, em estado de passividade, não teria ela sucumbido, isto é, perdido sua ipseidade e, por conseguinte, diluído a alteridade numa massa carnal? São, portanto, estas e outras questões que passaremos a esclarecer.

\section{O EU E O OUTRO COMO QUIASMA}

Antes de adentrarmos propriamente na discussão da problemática que norteia nossa investigação, qual seja, a relação entre o eu e o outro, propomos começar retornando ao início da obra $O$ visível e o invisível, a fim de trazermos à baila a noção de fé perceptiva, a qual será preponderante para compreendermos como a relação com outrem se encontra, primeiramente, ancorada numa dimensão, como veremos, de sentimento selvagem. 
É verdade que Merleau-Ponty já afirmara algo semelhante em 1945, mais exatamente através da noção de consciência pré-reflexiva e a vida perceptiva no geral. Porém, tratava-se aí, conforme comenta Ferraz, mais de explicitar o sentido da percepção, precisamente no momento de mostrar como "a atividade perceptiva adere ao mundo mesmo sem dispor de dados absolutamente certos e mesmo sem realizar verificações teóricas que atestem a certeza de suas visadas" (FERRAZ, 2009, p. 213, grifo do autor).

Em seu projeto ontológico, inversamente, Merleau-Ponty busca radicalizar a noção de fé perceptiva, ou seja, desvelar o contato com o Ser bruto, com a dimensão primitiva do mundo, de modo que, para isso, se faz necessário, justamente, interrogar a experiência ingênua tal como ela se mostra "ao homem natural” (MERLEAU-PONTY, 2014, p. 155). Ao contrário da percepção que tem um caráter de instituir significações, a fé perceptiva é a “fonte que alimenta e sustenta o sentir, o perceber e todas as formas de consciência. Porque a fé perceptiva é continuamente o solo que faz germinar a matéria bruta de todos os atos de percepção e ideação" (FALABRETTI, 2013, p. 315).

Nesse sentido, a fé perceptiva é dimensão do Ser pré-objetivo, pois independe da avaliação dos critérios lógicos e, portanto, objetivos. Os métodos científicos que possuem por objetivo a comprovação de algo "não nos permite compreender o que seja a fé perceptiva, precisamente porque é uma fé, isto é, uma adesão que se sabe além das provas" (MERLEAUPONTY, 2014, p. 37) ${ }^{7}$. A ciência, diz Merleau-Ponty, supõe a fé perceptiva, mas não a esclarece. Ocorre que o pensamento científico - e até a própria filosofia ${ }^{8}-$ se serve dessa instância primeira, se nutre dessa fé selvagem, mas, em um dado momento, rompe com essa experiência visível: "o universo do pensamento que se abre pela reflexão contém tudo o que é preciso para explicar o pensamento mutilado do início, que é a escada que se recolhe depois de ter subido" (MERLEAU-PONTY, 2014, p. 43).

A fé perceptiva enquanto saber natural da vida selvagem é sustentada por um logos endiathetos, o qual tem, por característica, expressar o sentido mudo que se efetiva "em cada um dos sentidos na constelação dos outros equivalentes que participam do mesmo mundo" (CHAUI, 2002, p. 120). Assim, a certeza das coisas e do outro nasce de um pertencimento comum ao sensível, que é expresso por um sentimento selvagem, uma experiência emocional e não de um saber tético. As crianças, diz Merleau-Ponty, são as que mais bem compreendem

\footnotetext{
${ }^{7}$ Não se trata, porém, de uma fé conforme comumente se atribui no sentido religioso. Ou seja, trata-se de uma fé fundada no mundo sensível, e não em um mundo metafísico.

8 “A filosofia é a fé perceptiva interrogando-se a si mesma”. (MERLEAU-PONTY, 2014, p. 103).
} 
essa experiência pré-tética: “A criança compreende muito além do que sabe dizer, responde muito além do que poderia definir, e, aliás, com o adulto, as coisas não se passam de modo diferente" (MERLEAU-PONTY, 2014, p. 24).

Segundo Falabretti (2013, p. 316), a fé perceptiva “oferece-nos não uma representação, mas o sentimento perpétuo de que estamos no mundo ligados às coisas e aos outros". Isto é, trata-se de um sentimento que está alhures das dicotomias do pensamento reflexivo, mas uma dimensão que permite a sustentação da relação com outrem. Conforme mostra Merleau-Ponty:

Como a coisa, como o outro, o verdadeiro cintila através de uma experiência emocional e quase carnal, onde as 'ideias' - as de outrem como as nossas - são antes traços de sua fisionomia e da nossa, e são menos compreendidas do que acolhidas ou repelidas no amor ou no ódio. (MERLEAU-PONTY, 2014, p. 24).

A passagem que acabamos de ler é significativamente esclarecedora. Primeiro porque a fé perceptiva nos revela que nossa relação com as coisas e com o outro ocorre não por decisão tética, mas por um sentimento selvagem, quase carnal. Segundo porque nessa "vida selvagem" - nível do Ser bruto - as coisas e outrem se encontram entrelaçados. Ou seja, a fé perceptiva não revela apenas que eu e o outro existimos, mas, fundamentalmente, que coexistimos, que estamos emaranhados um no outro. É justamente esse entrelaçamento - ou quiasma - o que procuraremos mostrar a partir de agora.

Numa nota datada de novembro de 1959, cujo título é precisamente O quiasma, Merleau-Ponty evidencia que tal noção busca superar as dicotomias entre o Para-si e Paraoutro e sujeito e objeto. O quiasma, enfatiza o filósofo, "faz com que pertençamos ao mesmo mundo, - um mundo que não é projetivo, mas que realiza a sua unidade através das incompossibilidades tais como a de meu mundo e do mundo do outro" (MERLEAU-PONTY, 2014, p. 200, grifo do autor). Assim, eu e o outro nos encontramos ancorados no mesmo Ser, ou seja, na mesma membrura ontológica que não encerra nossas ipseidades e, igualmente, não nos faz rivais, como vimos na ontologia sartriana": "o quiasma no lugar do Para Outro: isso quer dizer que não há apenas rivalidade eu-outrem, mas co-funcionamento. Funcionamos como um único corpo" (MERLEAU-PONTY, 2014, p. 200).

\footnotetext{
${ }^{9}$ Merleau-Ponty não deixa de notar, mais uma vez, o tratamento que Sartre concedeu à relação com o outro: “não se pode explicar esse duplo 'quiasma' pelo simples corte Para si e Em si. Faz-se necessário uma relação com o Ser que seja estabelecida do Interior do Ser - É, no fundo, o que Sartre procurava. Mas como para ele não existe senão a interioridade própria ao eu, e que o outro é sempre exterioridade, o Ser permanece em Sartre nãoencetado por essa descompressão que nele se processa, permanece positivamente pura, objeto, e o Para si só participa dele através de uma espécie de loucura” (MERLEAU-PONTY, 2014, p. 200, grifos do autor).
} 
Esse cofuncionamento em um único corpo em relação ao eu e o outro possui o mesmo sentido que vimos na seção anterior, mais especificamente quando falávamos da relação vidente-visível, senciente-sensível, os quais estão imbricados um no outro, como figura sobre um fundo, ou se quiser, entrelaçados carnalmente como uma gestalt. Assim, podemos exemplificar a relação com o outro, nessa perspectiva, como dois olhos que, embora um não tenha contato direto com o outro, se sabem existentes, pois estão assentados num mesmo corpo, e cofuncionam juntos para formarem a visão. Poderíamos, igualmente, dizer do exemplo das mãos, pois uma depende da outra para possibilitar a experiência tangível.

\footnotetext{
O que significa que cada visão monocular, cada palpação de uma única mão, embora tenha seu visível e seu tangível, está ligada à outra visão, à outra palpação de modo a realizar com elas a experiência de um único corpo diante de um único mundo, graças a uma possibilidade de reversão, de reconversão de sua linguagem na delas, possibilidade de reportar e de revirar segundo a qual o pequeno mundo privado de cada um não se justapõe àquele de todos os outros, mas é por ele envolvido, colhido dele, constituindo, todo juntos, um Senciente em geral, diante de um Sensível em geral. (MERLEAU-PONTY, 2014, p. 138).
}

A relação quiasmática com outrem impede, portanto, um mundo sobrepor o outro, justamente porque, por meio da reversibilidade, eles se transitam um no outro, e é isso que mantém cada qual em pleno funcionamento. De acordo com Merleau-Ponty, na reversibilidade não se faz necessário que um espectador esteja dos dois lados, por exemplo, de uma luva. É suficiente que, de um lado, "eu veja o avesso da luva que se aplica sobre o direito, que eu toque um por meio do outro (dupla 'representação' de um ponto ou plano do campo) o quiasma é isso: a reversibilidade” (MERLEAU-PONTY, 2014, p. 237).

Desse modo, Merleau-Ponty identifica a reversibilidade como uma espécie de "dobradiça" que amarra dois mundos e, ao mesmo tempo, preserva suas ipseidades. O eu e o outro, assim, são dois "antros, duas aberturas, dois palcos, onde algo vai acontecer - e ambos pertencem ao mesmo mundo, ao palco do Ser” (MERLEAU-PONTY, 2014, p. 237). Nesse sentido, o positivo e o negativo são “dois 'lados' de um Ser; já que no mundo vertical, todo o ser tem essa estrutura” (MERLEAU-PONTY, 2014, p. 207, grifos do autor).

O quiasma, como falamos, entrelaça o eu e o outro num mesmo tecido carnal no mundo sensível. Porém, Merleau-Ponty nos chama a atenção para o fato de que essa membrura ontológica, essa gestalt, não possibilita somente a troca entre o eu e o outro, mas também "troca de mim e do mundo, do corpo fenomenal e do corpo 'objetivo', do que se percebe e do percebido" (MERLEAU-PONTY, 2014, p. 200). Em outra passagem de $O$ 
visível e o invisível, o filósofo reforça essa ideia: "Nós nos colocamos tal como o homem natural, em nós $e$ nas coisas, em nós $e$ no outro, no ponto onde, por uma espécie de quiasma tornamo-nos os outros e tornamo-nos mundo" (MERLEAU-PONTY, 2014, p. 157, grifos do autor).

O eu e o outro e as coisas formam, assim, uma gestalt, uma unidade carnal originária. Essa unidade é, justamente, "o local geométrico das projeções e introjeções, a charneira invisível sobre o qual a minha vida e a vida dos outros giram para balouçar de uma para a outra a membrura da intersubjetividade" (MERLEAU-PONTY, 2014, p. 214). Desse modo, a relação com o outro é pautada nesse ponto de encontro que faz com que "se constituem a um tempo a diferença e a identidade das consciências e, consequentemente, a profundidade e a fenomenalidade do mundo" (FONTES FILHO, 2006, p. 18).

É relevante retomarmos brevemente a análise da experiência das mãos que se tocam. Como vimos, tal análise revelou a Merleau-Ponty que a relação senciente-sensível é indissociável, ou se quiser, gestáltica. Quando uma mão toca a outra, a mão tocada não é mais um objeto para a consciência, pois a reversibilidade faz com que a mão tocante também seja, ao mesmo tempo, tocada. Nosso próprio corpo vivencia em si mesmo certa relação de alteridade, quando ele próprio "prefigura esse contato e diferença com outrem, pois quando uma mão toca a outra o sujeito é, para si mesmo, já um outro" (JOHNSON; SMITH, 1990, p. 21).

Desse modo, as coisas, o mundo, e meu próprio corpo, são constituídos ontologicamente por quiasmas $^{10}$, por figura-fundo, por visível e invisível, por sencientesensível. Assim, considerando que todo visível contém uma invisibilidade, podemos dizer que eu sou para mim mesmo um invisível, no sentido de que não posso me ver vendo: "invisibilidade de nós mesmos como videntes, a invisibilidade de um olhar outro que me atinge sem que eu tenha condições de dizer de onde tenha partido" (MÜLLERGRANZOTTO, 2010, p. 31).

É na experiência da reversibilidade que temos no interior de nosso próprio mundo que constatamos a presença do outro, ou seja, a abertura para a alteridade já está precedida na própria estrutura da minha carne, a qual é também extensão da carne do próprio mundo,

\footnotetext{
10 "Em que sentido esses múltiplos quiasmas não fazem mais do que um só: não no sentido da síntese, da unidade originária sintética, mas sempre no sentido de Uebertragung, da imbricação, da irradiação do ser [...]: o mesmo não no sentido da idealidade nem da identidade real. $\mathrm{O}$ mesmo no sentido estrutural: mesma membrura, mesma Gestalthaft, o mesmo no sentido de abertura de outra dimensão do 'mesmo' ser [...]: daí no total um mundo que não é nem um nem 2 no sentido objetivo - que é pré-individual, generalidade" (MERLEAUPONTY, 2014, p. 235-236, grifos do autor).
} 
enquanto ser carnal. Em outros termos, a relação com o outro encontra seu fundamento não na ressignificação da subjetividade - do cogito -, ou no corpo. Por isso que não se trata mais de pensar a relação entre o eu e o outro em termos de intersubjetividade, ou intercorporeidade apenas, mas numa intermundaneidade. O que significa dizer que "é no próprio mundo que se encontrará a possibilidade do outro" (MERLEAU-PONTY, 2014, p. 169). Ou seja, a abertura para outrem não está mais no cogito tácito nem no corpo, mas no mundo. Tanto o mundo sensível, quanto o mundo histórico, diz Merleau-Ponty (2014, p. 87), são sempre intermundos.

Após constatarmos que o mundo, ontologicamente, contém a abertura para outrem, resta ainda mostrar como esse outro aparece para o eu, ou seja, como posso dizer que ele é um outro. A resposta a essa questão pode ser encontrada, justamente pelo fato de que outrem se faz sensível e é também um Ser senciente, por ser a outra mão, ou o outro lado da gestalt, que ele pode entrar em meu mundo, me descentrar ${ }^{11}$ da posição que eu julgava ter soberania ${ }^{12}$.

Para que o outro seja verdadeiramente outro não basta e não é preciso que seja um flagelo, a contínua ameaça de reviravolta absoluta do para e do contra, juiz posto acima de toda contestação, sem lugar, sem relatividades, sem rosto, como uma obsessão, e capaz de esmagar-me com um olhar na poeira do meu próprio mundo. É necessário e suficiente que tenha o poder de descentrar-me, opor sua centração à minha, e ele o pode unicamente porque não somos duas nadificações instaladas em dois universos de Em Si incomparáveis, mas duas entradas para o mesmo Ser, cada uma acessível apenas a um de nós, aparecendo, entretanto, para o outro, como praticável de direito, porquanto ambas fazem parte do mesmo Ser. (MERLEAUPONTY, 2014, p. 85, grifos do autor).

Nessa esclarecedora passagem, Merleau-Ponty refuta, novamente, a perspectiva sartriana da intersubjetividade, ao mesmo tempo em que evidencia como o outro se configura para o eu. A relação com outrem não é pensada mais em termos de contradição radical ${ }^{13}$, como negação da minha existência. Outrem, diz Merleau-Ponty numa nota de novembro de 1960, não é mais uma liberdade vista por fora como destino e fatalidade, ou como um sujeito rival do outro, "mas um prisioneiro no circuito que o liga ao mundo, como nós próprios, e

\footnotetext{
${ }^{11}$ É com o conceito de descentramento que Merleau-Ponty, na obra A prosa do mundo, descreve a relação com o outro, tanto na dimensão sensível, quanto na linguagem.

${ }^{12}$ Como bem nos lembra Falabretti (2013, p. 325): “o outro é, nesse sentido, uma fonte filosófica, pois me ensina a rever o mundo, a encontrar nas coisas, nele mesmo e em mim algo além daquilo que eu acreditava ver, sentir e ser".

${ }^{13}$ Barbaras mostra, com precisão, a diferença entre a noção de contradição entre o eu e o outro em Sartre e em Merleau-Ponty. Diz aquele: "Para Sartre, não há relação com o outro que não seja conflituosa, da comunicação que não implique de um antagonismo; para Merleau-Ponty, inversamente, a contradição é sempre uma modalidade da comunicação, de uma harmonia originária que nenhum conflito pode romper absolutamente." (BARBARAS, 1991, p. 160-161).
} 
assim também no circuito que o liga a nós - E este mundo nos é comum, é intermundo" (MERLEAU-PONTY, 2014, p. 241, grifo nosso).

É por estar emaranhado no mesmo tecido carnal que "não preciso buscar os outros ao longe: encontro-os na minha experiência, instalados nos vãos que indicam o que eu não vejo e eles veem" (MERLEAU-PONTY, 1967, p. 186). Não obstante outrem esteja "junto" a mim, não tenho acesso a ele de maneira direta, ele será sempre um invisível, ausência da qual eu não posso apreender por inteiro ${ }^{14}$. Todavia, segundo Merleau-Ponty, não se trata de uma ausência qualquer, mas de certa ausência, que nos é comum, que predestinem o outro a ser o espelho de mim mesmo, como eu sou dele, fazendo com que eu e ele não sejamos "duas imagens lado a lado, mas uma única imagem, onde ambos estamos implicados, que minha consciência de mim mesmo e o meu mito do outro sejam não duas contraditórias, mas o avesso uma da outra" (MERLEAU-PONTY, 2014, p. 85-86).

\section{CONCLUSÃO}

É diante do fato de que não somos mais dois contraditórios que se excluem um ao outro, mas dois cúmplices encarnados frente ao mistério do mundo, que Merleau-Ponty restitui a relação entre o eu e o outro em sua ontologia da carne. A grande novidade de sua teoria da alteridade, nessa última fase - apesar de inacabada - de sua filosofia, pode ser resumida com a seguinte passagem presente em uma nota de trabalho de 16 de novembro de 1960:

O que trago de novo ao problema do mesmo e do outro? Isto: que o mesmo seja o outro de outro, e a identidade diferença de diferença - isso 1) não realiza superação, dialética, no sentido hegeliano 2) realiza-se no mesmo lugar, por imbricação, espessura, espacialidade (MERLEAU-PONTY, 2014, p. 237, grifo do autor).

O eu e o outro constituem, a partir dessa passagem, uma gestalt na qual a identidade se realiza por meio da diferenciação. Não se trata mais de uma relação de ego e alter $e g o$, na qual a existência do segundo é fundada da representação do primeiro. Ao contrário, o eu e o outro, agora, estão perpassados por uma dimensão de generalidade carnal que, por sua natureza, é

\footnotetext{
${ }^{14}$ Sobre a localização de outrem, Merleau-Ponty na nota de setembro de 1959 coloca a seguinte questão: "Onde está o outro neste corpo que vejo? Ele é (como o sentido da frase) imanente ao corpo (não se pode destacá-lo para pô-lo à parte) e, contudo, é mais do que a soma dos signos ou significações por ela veiculados. É aquilo de que as significações são sempre imagem parcial e não exaustiva - e que, contudo, atesta estar presente por inteiro em cada uma delas. Encarnação inacabada sempre em curso.“(MERLEAU-PONTY, 2014, p. 196).
} 
feito de entradas, entrelaçamentos, e que a relação com o outro é mais uma dessas experiências. Assim, na relação com o outro a experiência da diferenciação ocorre precisamente porque cada um "percebe no outro uma diferença com relação a um terceiro, que se apresenta como fundo de generalidade, a partir da qual as duas imagens, o eu e o outro, encontram-se entrelaçadas" (ALVARENGA, 2016, 139). Nesse sentido, entendemos que os problemas derivadas do pensamento objetivista e intelectualista que barravam a experiência do outro é, de uma vez por todas, superados a partir dessa nouvelle ontologie merleaupontyana, fundada não numa noção de Ser como pura identidade, nem como substância, mas como gestalt, ou seja, como estrutura que se caracteriza por diferenciação interna.

\section{REFERÊNCIAS}

ALVARENGA, Rodrigo. Alteridade e fenomenologia das psicoses: outrem em MerleauPonty e Binswanger. 2016. 234f. Tese (Doutorado) - Universidade Federal de Santa Catarina, Florianópolis, 2016.

BARBARAS, Renaud. De l'être du phénomène: sur l' ontologie de Merleau-Ponty. Grenoble: Jérôme Millon, 2001.

CHAUI, Marilena. Experiência do pensamento: ensaios sobre a obra de Merleau-Ponty. São Paulo: Martins Fontes, 2002.

FALABRETTI, Ericson. Estrutura e ontologia na obra de Merleau-Ponty. Revista de Filosofia Aurora, Curitiba, v. 25, n. 37, p. 305-341, jul./dez., 2013.

FERRAZ, Marcus Sacrini Ayres. Fenomenologia e ontologia em Merleau-Ponty. Campinas, SP: Papirus, 2009.

FONTES FILHO, Wosvaldo. Considerações sobre o lugar da alteridade em Merleau-Ponty. Reflexão, Campinas, v. 31, n. 89, p. 11-23, jan./jun., 2006.

JOHNSON, Galen A.; SMITH, Michel B (Ed.). Ontology and alterity in Merleau-Ponty. Illinois: Nortwestern University, 1990.

MERLEAU-PONTY, Maurice. Les aventures de la dialectique. Paris: Gallimard, 1967.

MERLEAU-PONTY, Maurice. O olho e o espírito. São Paulo: Cosac Naify, 2013.

MERLEAU-PONTY, Maurice. O visível e o invisível. 4. ed. São Paulo: Perspectiva, 2014.

MOUTINHO, Luiz Damon Santos. O invisível como negativo do visível: a grandeza negativa em Merleau-Ponty. Tras/Form/Ação, Marília, v. 27, n. 01, p. 7-18, jan./jul., 2004. 
MÜLLER-GRANZOTTO, Marcos José. Outrem em Husserl e em Merleau-Ponty. In. BATTISTI, César Augusto (Org.). Às voltas com a questão do sujeito: posições e perspectivas. Cascavel: Unijuí; Edunioste, 2010. p. 315-333.

RAMÍREZ, Mario Teodoro. La filosofia del quiasmo: introducción al pensamiento de Merleau-Ponty. México: FCE, 2013.

RIMBAUD, Arthur. Carta a George Izambard. [1871] Tradução de Marcelo Jacques de Moraes. Alea: Estudos Neolatinos [online], Rio de Janeiro, v. 08, n. 01, p. 154-163, jan./jun., 2006. Disponível em:

http://www.scielo.br/scielo.php?script=sci_arttext\&pid=S1517-106X2006000100011. Acesso em: 20 jan. 2018. 